\title{
Sobre gramática tradicional, ainda uma vez
}

\author{
Ricardo CAVALIERE (1) \\ Universidade Federal Fluminense (UFF), Liceu Literário Português
}

\section{RESUMO}

Este estudo renova um olhar sobre a gramática tradicional, suas bases e características essenciais, bem como sua crítica no panorama dos estudos linguísticos contemporâneos. São tratados temas como o da imprecisão do conceito de tradição linguística, o viés peculiar de que semelhante con-

อ

\section{OPEN ACCESS}

EDITADO POR

- Gonçalo Fernandes (UTAD)

- Leonardo Ferreira Kaltner (UFF)

- Ronaldo Batista (UPM)

AVALIADO POR

- Marli Quadros Leite (USP)

- Leonardo Gueiros (UFPB)

\section{DATAS}

- Recebido: 03/09/2021

- Aceito: 23/09/2021

- Publicado: 07/12/2021

\section{COMO CITAR}

Cavaliere, R. (2021). Sobre gramática tradicional, ainda uma vez. Revista da Abralin, v. 20, n. 3, p. 493-510, 2021. ceito goza no meio acadêmico brasileiro, bem como as características genéricas que as várias vertentes da gramatica tradicional apresenta em plano historiográfico.

\section{ABSTRACT}

This paper renews a look at the traditional grammar, its bases and essential characteristics, as well as its critique in the set of contemporary linguistic studies. Its contents discuss topics such as the concept of linguistic tradition, the peculiar bias that such a concept has in the Brazilian academic panorama, as well as the generic characteristics that the various strands of traditional grammar present in historiographical terms.

\section{PALAVRAS-CHAVE}

Gramática tradicional. Conceito. Avaliação.

\section{KEYWORDS}

Traditional grammar. Concept. Evaluation. 


\section{REVISTA DA ABRALIN}

\section{O significado cultural de tradição}

O termo tradição, do latim traditio, onis, significa etimologicamente "entrega", "a ação de dar algo a alguém". Em acepção mais simples, entende-se tradição como produto do passado que continua a ser aceito e pertinente no presente, ou seja, um conjunto de costumes e práticas socialmente enraizados que caracterizam o patrimônio cultural da sociedade. Em relação a este significado geral, tradição implica um conjunto de crenças e regras morais herdadas do passado que determinam o comportamento social humano nos dias atuais. O conceito de tradição não implica que seja transmitida necessariamente por meio da língua, uma vez que os meios de se estabelecer um legado no campo da religião e da cultura, em geral, podem se restringir a códigos não verbais em que predominam atitudes e exemplos.

Mas, junto com a ideia de "transmissão", que está imersa no sentido da tradição, surge um segundo sentido de natureza subjetiva: tradição implica a consciência dos valores transmitidos e de sua continuidade (cf. CARVALHO, 1969, p. 205). Mais do que isso, a tradição implica a necessidade de manter viva essa consciência, pois será essa atitude consciente que manterá firme a base axiológica que sustentará as mudanças que a modernidade impõe. Esta consciência permanente no processo histórico de transmissão, incluindo ideias, conceitos, hábitos e saberes ancestrais, manifesta-se com um sentimento de tradição acronológica, não exclusivamente ligada ao passado, mas infiltrada em atos e comportamentos modernos. Ou seja, citando o linguista português Herculano de Carvalho (1924-2001), "tradição (a própria palavra diz) não é quietude, mas movimento em continuidade" (1969, p. 206).

Assim, podemos dizer que tradição implica preservação de valores, comportamentos e atitudes atuais que se mostraram eficazes no passado. Nessa perspectiva, há um vínculo semântico imperativo entre idoneidade moral e tradição, no sentido de que, do ponto de vista cultural, cada povo cria filtros que funcionam para permitir apenas a sobrevivência do que se mostrou relevante para manter e proteger seus valores fundamentais. Por outro lado, deve-se observar que a tradição é fonte de autoridade, fato que deve ser levado em consideração quando, por exemplo, observamos em todas as comunidades sociais uma relação hierárquica entre idosos e jovens, educados e iletrados, parentes e estranhos, em que sempre se confere aos primeiros maior argumento de autoridade do que aos segundos.

Com efeito, na perspectiva de Max Weber (1864-1920) sobre o conceito de autoridade social, uma das três formas de dominação legítima caracteriza-se por "apoiar-se numa crença pautada na santidade das tradições imemoráveis" $(1968,215)^{1}$. Esta forte presença da tradição na avaliação axiológica das coisas em geral, que contribui decisivamente para a aceitação da autoridade e estratificação hierárquica, pode ser observada na relação entre as conquistas das teorias linguísticas e as práticas pedagógicas no ensino de língua vernácula, em que as últimas situam-se naturalmente mais próximas de ideias tradicionais do que das novas propostas revolucionárias.

Interessante notar que, em dimensão mais ampla, no que diz respeito a seu sentido cultural, a tradição deve expressar um conceito de continuidade, a sensação de que algo já passou no tempo e

\footnotetext{
${ }^{1}$ No original, "resting on an established belief in the sanctity of immemorial traditions".
} 


\section{REVISTA DA ABRALIN}

vai continuar no futuro, de tal sorte que a obediência aos princípios e regras tradicionais se interprete como um valor que permanece sem solução de continuidade ${ }^{2}$. Esse perfil de valores tradicionais, em certa medida, colide com o uso do termo tradição na história da ciência, em particular na história da linguística, conforme veremos a seguir. No entanto, o uso amplo e diversificado do termo nas disciplinas de humanidades certamente pode influenciar sua presença nos estudos doutrinários históricos, o que contribui para agregar mais imprecisão a seu significado.

\section{O conceito de tradição nos estudos linguísticos}

Em seu artigo sobre modelos em historiografia da linguística (1989), Konrad Koerner observa que, quando uma certa ideia começa a cativar a atenção da comunidade científica, outras, sejam mais antigas, sejam mais recentes, mantêm-se em evidência. Em outras palavras, certo modelo teórico que dominou a linguística por um determinado período torna-se menos influente, a partir de certo momento, para voltar a viger no futuro. Essa renovação não implica alternância dialética, como se poderia pensar na concepção hegeliana do desenvolvimento da ciência, mas uma coexistência de modelos distintos em que se estabelece uma relação de continuidades e descontinuidades. A referência de Koerner a "tradições linguísticas", em consonância com o ideário de outros teóricos ${ }^{3}$, atribui ao termo tradição uma noção discreta em vez de contínua ${ }^{4}$. Nessa abordagem historiográfica, podemos identificar várias "tradições" - aqui o termo poderia adquirir um sentido próximo ao conceito de paradigmas em Thomas Kuhn (1970) - que avançam no tempo e se alternam em períodos de maior ou menor evidência. Às vezes, o termo tradição refere-se a um legado particular de acordo com o horizonte de retrospecção do autor. Poderíamos citar alguns exemplos esparsos aqui:

\footnotetext{
${ }^{2}$ Uma tentativa controversa de caracterização da "tradição autêntica" - que deve ter três atributos: perdurar por ao menos três gerações, transmitir a ideia de passado no presente e expressar o sentido de continuidade - pode ser encontrada em Gross (1992:10).

${ }^{3}$ Sylvain Auroux, por exemplo, afirma que "l'origine d'une tradição peut être spontanée ou résulter d'un transfert technologique. La tradition latine est le résultat d'un transfert, de même la grammaire hébraïque, ainsi que l'étude des venaculaires européens, améridiens, africains, etc." (1989, p. 22). Dell Hymes (1927-2009), também, aplica este sentido ao termo tradição, a ponto de se referir a uma tradição de certo autor (a tradição de Sapir, por exemplo) (1972, p. 278). O mesmo em Matthews (2001, p. 24) sobre a "tradição saussuriana".

${ }^{4}$ Em seus ensaios sobre filosofia clássica, lidando com as dificuldades para definir os parâmetros das escolas filosóficas, Michael Frede (1940-2007) usa o termo tradição tanto no sentido discreto quanto no sentido contínuo: "we will never be able to understand medieval philosophy in its various traditions (the traditions of Byzantine philosophy, Islamic philosophy, and the Latin West) unless we understand the philosophy of late antiquity" (...) The Categories, ascribed to Aristotle, has played a unique role in our tradition [my emphasis], since it is the only philosophical treatise that has been the object of scholarly and philosophical attention continuously [my emphasis ] since the first century B.C., when people first began writing commentaries on classical philosophical texts" (1987, p. XX-XXI)
} 


\section{REVISTA DA ABRALIN}

O pai de Saussure era zoólogo e entomologista e, antes de se especializar em linguística indo-europeia, Saussure estudou, na esteira de uma tradição familiar de cerca de cento e cinquenta anos, matemática, física e química na Universidade de Genebra (KOERNER, 1975, p. 707). ${ }^{5}$

Assim, apesar da tradição rigorosa e das muitas passagens abrangentes no tratado em que a tradição se baseia, o único tipo de palavra inequivocamente referido por Locke em sua tese de que palavras significam ideias é o "nome" (KRETZMANN, 1975, p. 335). ${ }^{6}$

Temos ciência, no entanto, de uma forte tradição da gramática especulativa um século ou dois depois, e não é de surpreender que algumas das principais figuras dessa tradição fossem da Espanha (TRENTMAN, 1975, p. 296). ${ }^{7}$

Trata-se do entendimento há muito tempo firmado e abundantemente exemplificado de que os primeiros gramáticos que se empenharam em descrever o francês, assim como outras línguas vernáculas, a partir do Renascimento, fizeram-no mediante uso das categorias e noções desenvolvidas pela tradição secular dos gramáticos latinos (FOURNIER, 2007, p. 17). ${ }^{8}$

(...) podemos traçar várias correntes de estudos linguísticos que desaguam na tradição europeia e tornando-se parte dela em diferentes momentos, resultando, assim, a ciência linguística como o mundo a conhece hoje (ROBINS, 1967, p. 6$){ }^{9}$

Em outra perspectiva, acreditamos ser possível falar de uma tradição linguística que não se segmenta em movimentos discretos, visto caracterizar-se em um plano mais abstrato no qual encontramos ideias que foram sedimentadas ao longo do tempo e, devido a sua aceitação especial no meio acadêmico, não pertencem mais a uma "tradição particular", mas a esse plano mais amplo de uma tradição lato sensu. Como regra geral, a referência a essa tradição atemporal ou inespecífica no discurso científico não é feita pelo substantivo tradição, mas pelo advérbio tradicionalmente, que se refere a esse saber consolidado no curso da história da linguística. Isso se evidencia nas seguintes citações:

\footnotetext{
${ }^{5}$ No original, "Saussure's father was a zoologist and entomologist, and before specializing in Indo-European linguistics, Saussure studied, in line with a family tradition of some one-hundred-and-fifty years, mathematics, physics, and chemistry at the University of Geneva'.
}

${ }^{6}$ No original, "Thus, despite the critical tradition and the many broad passages in the Essay on which the tradition is founded, the only kind of word unmistakably referred to by Locke in his thesis that words signify ideas is the "name".

${ }^{7}$ No original, "We do know, however, about a strong tradition of speculative grammar a century or two later, and not surprisingly some of the primary figures in this tradition were from Spain".

${ }^{8}$ No original, "C'est une idée depuis longtemps établie et abondamment illustré que les premiers grammairiens qui s'efforcent de décrire le français, comme d'autres langues vernaculaires à partir de la Renaissance, procédent utilisant le catégories et les notions développées par la tradition plusiers fois séculaire des grammariens du latin".

${ }^{9}$ No original, "we can trace several streams of linguistic studies flowing into the European tradition and becoming part of it at different times, thereby to constitute linguistic science as the world knows it today". 


\title{
REVISTA DA ABRALIN
}

\begin{abstract}
Mas se uma língua é um sistema, então, como parte desse sistema, we está relacionado a outras palavras: mais obviamente a I, you, us e outras que são tradicionalmente denominadas pronomes (MATTHEWS, 2001, p. 6). ${ }^{10}$

Uma gramática é tradicionalmente a descrição de "uma língua" e, portanto, pode ser "vista" como Harris a vê em um artigo [...] (MATTHEWS, 2001, p. 25). ${ }^{11}$

A noção de gênero implica a possibilidade de identificar características formais tradicionalmente reconhecidas (HYMES, 2001, p. 61) ${ }^{12}$.
\end{abstract}

O que temos aqui, então, não são propostas pontuais, mas conceitos arraigados que perdem sua identidade paradigmática para constituir um conhecimento consolidado que é acatado de maneira geral. Considerando que paradigmas ou "tradições" avançam paralelamente, conclui-se que, ao longo do tempo, alguns dos seus conceitos "sobrevivem" em momentos de descontinuidade e permanecem válidos ou em coexistência com os conceitos do paradigma em vigor. Segue-se, portanto, a construção de uma ordem conceitual perene, que, por isso, assume um caráter acronológico, pois se desvincula das tradições que lhe deram origem. É o que ocorre, por exemplo, com a noção de classes gramaticais, a figura sintática do sujeito, o conceito de morfema como unidade mínima significativa, a predicação verbal etc.

Por outro lado, a vigência dessa tradição acronológica faz consolidar a metalinguagem correspondente, fato que não raro provoca polissemia no tocante a certos metatermos consagrados na teoria linguística, conforme se verifica, no plano morfológico, na noção de nome e de verbo. Em suma, conquistas teoréticas como o conceito de universais linguísticos, unidades morfológicas, classes de palavras e tantas outras surgidas no processo de continuidades e descontinuidades dos modelos de investigação passam a integrar uma única tradição acronológica, visto que permanecem válidos para além das fronteiras temporais de seus respectivos paradigmas. De certa forma, esse fato está intimamente vinculado ao que Robins (1921-2000) denomina "acúmulo progressivo de conhecimento em um determinado intervalo" (1967, p. 13) ${ }^{13}$.

Nesse aspecto, como se percebe, especial importância deve ser atribuída à metalinguagem. A tarefa de falar de uma língua para descrevê-la e instrumentalizá-la resulta na produção de dois pilares do conhecimento metalinguístico: as gramáticas e os dicionários. Esses produtos, ou tecnologias - como os categoriza Sylvain Auroux quando trata do processo de gramatização das línguas (1992) - , sofrem o desgaste natural que o avanço tecnológico impõe a qualquer campo do conhecimento. Como resultado, a passagem do tempo e a atividade contínua da pesquisa científica implicam

\footnotetext{
${ }^{10}$ No original, "But if a language is a system then, as part of that system, we is related to other words: most obviously to I, you, us and others that are traditionally called pronouns".

${ }^{11}$ No original, "A grammar is traditionally a description of 'a language', and could therefore be 'viewed', as Harris puts it in one paper".

${ }^{12}$ No original, "The notion of genre implies the possibility of identifying formal characteristics traditionally recognized".

${ }^{13}$ No original, "progressive accumulation of knowledge in a given range".
} 


\section{REVISTA DA ABRALIN}

uma mudança tecnológica inexorável que gera uma gama antagônica de saberes bem estabelecidos e de saberes descartados. De acordo com o conceito de "ciência normal" proposto por Thomas Kuhn, o choque entre paradigmas envolve a própria concepção de ciência e seu escopo. Kuhn ilustra esse fato com o conflito entre a química de Lavoisier e a química flogística do século XVIII, o primeiro desinteressado em pesquisas sobre a semelhança entre os metais, o último dedicado a esta questão (KUHN, 1970, p. 148). Na linguística, o fato pode ser exemplificado pelo total desinteresse do estruturalismo pela origem da linguagem, que foi o foco obsessivo da escola histórico-comparativa no século XIX.

Caberá ao próprio Kuhn advertir que os novos paradigmas mantêm vínculos com os anteriores: "eles normalmente incorporam muito do vocabulário e do aparato, tanto conceitual quanto manipulador, que o paradigma tradicional havia empregado anteriormente" $(1970 \text {, p. 149) })^{14}$. Pois bem, manter a mesma metalinguagem em diferentes modelos teóricos, além de acrescentar novos conceitos à terminologia técnica anterior, resulta em preservar indiretamente os conceitos que essa terminologia expressava, mesmo que apenas para estabelecer o necessário confronto entre o que o metatermo significava antes e o que passa a expressar depois. Este é um fator que confere à tradição um traço atemporal, pois é veiculada em uma metalinguagem que não está ligada exclusivamente ao presente ou ao passado.

Podemos ilustrar esse fato com a noção de sujeito. Este é um conceito gramatical antigo que desafia a teoria linguística até os dias atuais. A história da linguística atribui seu surgimento à lógica aristotélica e o identifica como um legado da tradição clássica, o que poderia ser entendido como um ganho teórico herdado do passado. No entanto, as crescentes discrepâncias teóricas sobre o conceito de sujeito nos paradigmas subsequentes atuam como um renascimento permanente das ideias aristotélicas, ou seja, atuam necessariamente como ratificação ou retificação das teorias de Aristóteles, de modo que suas ideias integrem necessariamente os fundamentos teóricos renovados como pano de fundo. A psicolinguística de Hermann Steinthal (1823-1899) atribuiu à noção de sujeito um significado que lhe confere maior abstração na camada profunda da frase. Conforme Steinthal comenta na análise do exemplo O paciente dormiu bem, a tradição aristotélica reconhece o paciente como sujeito e dormiu bem como predicado, significando que paciente é o termo sobre o qual algo é dito, e dormir bem é o que sobre ele se diz. No entanto, em uma interpretação pautada no plano semântico da intencionalidade do falante, a frase é construída para afirmar que o sono do paciente foi bom, o que levaria a outra análise em que o sujeito seria "o sono do paciente" e o predicado o advérbio bem (apud SEUREN, 1999, p. 44).

Em outra perspectiva, Georg von der Gabelentz (1840 - 1893), em seu Die Sprachwissenschaft (1891), trata do conceito de sujeito e predicado psicológico que pode não ter correspondência com suas contrapartes gramaticais, ou mesmo não corresponder a nenhum item lexical. Essa tese, aliás, foi explorada pelo linguista brasileiro Manuel Said Ali (1861-1953) para descrever o mecanismo

\footnotetext{
${ }^{14}$ No original, "they ordinarily incorporate much of the vocabulary and apparatus, both conceptual and manipulative, that the traditional paradigm had previously employed".
} 


\section{REVISTA DA ABRALIN}

sintático do sujeito indeterminado com a partícula se em português (2008 [1908]). Considerando outras propostas, podemos citar a análise estruturalista das línguas ergativas, nas quais a noção de sujeito está atrelada a traços morfológicos, uma vez que a morfologia do sujeito difere conforme a transitividade do verbo. Hoje em dia, a pragmática nos dá uma interpretação clara e distinta de sujeito e tópico na estrutura sintática da frase, mais uma vez desafiando a premissa de Aristóteles de que o sujeito situa-se em um termo gramatical que figura como alvo da predicação.

Todas essas referências justificam-se para demonstrar que a carga semântica que o metatermo sujeito carrega em cada uma das tradições mencionadas implica a consideração do sentido aristotélico original, ou seja, a preservação deste metatermo no devir da investigação linguística sempre trará à tona implicitamente a concepção de Aristóteles, mesmo em instâncias que procuram contestá-la. A metalinguagem, portanto, confere um caráter de atemporalidade à tradição, uma vez que a força de designação do metatermo se expressa em uma polissemia que engloba conceitos científicos anteriores e novos a ele imanentes. Em suma, em arremate ao exemplo de que nos servimos, do ponto de vista metalinguístico, a preservação do metatermo "sujeito" até os dias atuais mantém viva a tradição aristotélica, ainda que seus fundamentos originais já não se considerem necessariamente válidos.

\section{Gramática tradicional: fácil de reconhecer, difícil de definir}

Tem crescido o interesse dos estudos historiográficos sobre os parâmetros e escopos da denominada gramática tradicional, conforme se pode observar em publicações recentes no Brasil (cf. especialmente VIEIRA, 2018 e CAVALIERE, 2015). Objeto de veneração e desprezo, a gramática tradicional habita o imaginário dos que se dedicam ao estudo linguístico em diferentes matizes, de que resulta mesmo concluir ser daquelas coisas que todos identificam, mas poucos logram definir. No Brasil, em especial, o conceito e domínio da gramática tradicional, por vários motivos, gozam de uma distinção idiossincrática, de que decorre certa referenciação caótica a suas bases, via de regra taxadas simploriamente como puristas e excessivamente normativas, fato que, para além de insultar o próprio conceito de tradição em linguística, deixa transparecer certo obscurantismo acerca de seu verdadeiro perfil.

Em um texto publicado há quase três décadas, Jean-Claude Chevalier (1925-2018) faz uma crítica contundente aos gramáticos gerativistas por causa de seu usual desprezo à gramática tradicional, sem que demonstrem sequer se efetivamente a compreendem (1986, p. 289). Poderíamos estender a crítica a muitos linguistas filiados a outros paradigmas, uma vez que, em geral, percebe-se um conceito amplo e impreciso do que seja a gramática tradicional na concepção de estudiosos filiados a diferentes modelos de investigação. Esse fato pode decorrer da própria imprecisão que ainda caracteriza a competência e os domínios da linguística como ciência. Além disso, conforme o próprio Chevalier observa, a concepção da gramática tradicional como um produto cultural a partir do século 


\title{
REVISTA DA ABRALIN
}

XVIII implica um propósito que vai além do ensino de línguas, ou seja, "a gramática exerce ao mesmo tempo o papel de formação da personalidade e o papel de formação científica" $(1986, \text { p. 290) })^{15}$.

Muitos são os exemplos que poderiam ser citados aqui sobre a concepção imprecisa da gramática tradicional, tais como a de Keith Allen, em seu The Western classical tradition in linguistics (2009), no qual ora vincula a ideia de tradição à gramática clássica greco-latina (p. 12), ora à gramática medieval racionalista (p. 13), ou mesmo a uma vertente inespecífica (p. 127). Michael Frege, por sua vez, afirma o que entende por gramática tradicional (1987, p. 338):

\begin{abstract}
[...] modelo de sistema gramatical estabelecido e pressuposto por gramáticas modernas do grego e do latim, como em Kühner-Gerth ou Kühner-Stegmann. Uma vez que gramáticas desse tipo têm sido tradicionalmente seguidas de perto por gramáticos de outras línguas, pode-se falar de gramática tradicional de forma bastante geral. ${ }^{16}$
\end{abstract}

Em outra dimensão, ao se referir-se às "três gramáticas" - gramática estrutural, gramática histórica e gramática tradicional -, Francisco Adrados (1922-2020) vislumbra uma identidade entre a "gramática estrutural" e a "gramática tradicional", de origem grega, uma vez que ambas estão engajadas na descrição de um estado de lingua, além de partir do pressuposto de que os elementos que integram um estado de língua não são independentes ou inconsistentes, "porém formam um todo organizado, um sistema cujas partes são interdependentes" (1969, p. 21) ${ }^{17}$. Esse propósito colocaria ambas as gramáticas em extremos opostos: de um lado, a gramática tradicional acompanhada pela gramática estruturalista e, de outro, a gramática histórica. Além disso, Adrados enfatiza que a identidade entre a gramática tradicional e a gramática estrutural reside no enfoque das regularidades da língua, seja a partir da palavra, seja nas regras sintáticas, o que obviamente não pode ser atribuído à perspectiva diacrônica da gramática histórica.

Um fato que deve ser considerado consiste em que, na concepção de Adrados, a característica mais evidente da gramática tradicional, que a define como "arte de falar e escrever corretamente", desaparecida no plano da gramática histórica, mantém-se viável (não imprescindível) na gramática estrutural, embora nessa última o propósito ou escopo primacial seja eminentemente científico (1969, p. 24). Em linguistas como Eugenio Coseriu (1921-2002), o conceito de gramática tradicional não se baseia em critérios cronológicos, porém em critérios epistemológicos, segundo os quais a tradição gramatical "é em grande parte uma gramática lógica, baseada essencialmente na ideias da correspondência ou equivalência entre as categorias lógicas e as categorias gramaticais" (1986, p. 17) ${ }^{18}$.

\footnotetext{
${ }^{15}$ No original, "la grammaire joue en même temps un rôle de formation de la personalité et un rôle dans la formation scientifique".

${ }^{16}$ No original, "the kind of grammatical system set out in and presupposed by standard modern grammars of Greek and Latin like Kühner-Gerth or Kühner-Stegmann. Since grammars of this kind traditionally have been followed quite closely by grammarians of other languages, one may speak of traditional grammar quite generally".

${ }^{17}$ No original, 'sino que forman um todo organizado, un sistema cuyas partes son interdependientes".

${ }^{18}$ No original, "es en gran parte una gramática lógica, basada esencialmente em la idea de la correspondencia o equivalencia entre las categorías lógicas y las categorías gramaticales”.
} 


\section{REVISTA DA ABRALIN}

Em suma, o arcabouço doutrinário, hoje, ainda carece de uma visão clara e objetiva (muito menos pacífica) acerca da gramática tradicional como um produto da atividade científica e ferramenta para a formação dos indivíduos no exercício da cidadania. No entanto, poderíamos chegar a um perfil desse tipo de gramática atestando algumas características fundamentais. Assim, a gramática tradicional é ordinariamente reconhecida por: a) desempenhar um papel deontológico; b) ter finalidade dual, descritiva e pedagógica; c) usar uma metalinguagem comum a várias tradições linguísticas; d) servir-se de corpus em texto escrito literário. Essas são as características que se podem reconhecer como "traços categóricos" da gramática tradicional em perspectiva genérica, mormente as de letras a e $d$; por outro lado, muitas gramáticas inscritas em diferentes tradições linguísticas, ou seja, produzidas sob perspectivas teóricas distintas, acabam por ser indiscriminadamente identificadas como tradicionais por deterem essas características tão peculiares.

O fato revela-se frequentemente em teses e dissertações sobre descrição linguística em que o autor opta por traçar uma referência à tradição gramatical antes de aplicar a teoria escolhida para descrever o fato linguístico. Via de regra, os títulos e autores selecionados advêm deste conceito impreciso de que "se é normativo, é tradicional", de tal sorte que obras resultantes de distintos aparatos teóricos, e, portanto, heterogêneas, são reunidas sob a mesma rubrica da "tradição". Pinçamos um exemplo em uma qualificada dissertação de mestrado (LIMA-HERNANDES, 1998), em que a autora descreve o mecanismo sintático das orações temporais em perspectiva funcionalista. Ao referirse à abordagem tradicional do tema, a autora identifica com o mesmo rótulo "tradicional" nomes como Manuel Said Ali (1861-1953), formado no paradigma filológico do século XIX, Carlos Henrique da Rocha Lima (1915-1991) e Evanildo Bechara, herdeiros da perspectiva filológica e seguidores de teses estruturalistas em suas conhecidas gramáticas, Celso Cunha (1917-1989) e Luís Lindley Cintra (1925-1991), cuja Nova gramática do português contemporâneo (1985) dedica as primeiras páginas à aplicação do variacionismo laboviano, e mesmo Maria Helena Mira-Mateus (1931-2020) et alii, cuja Gramática da língua portuguesa $(1983)^{19}$ pouco tem de normativa, além de ser fiel ao estruturalismo funcional, com expressiva incursão nos fundamentos da gramática gerativa.

Essa referência, escolhida fortuitamente em bancos de teses, apenas visa a comprovar que vige um conceito supraparadigmático de gramática tradicional, decerto em face da imprecisão que o termo "tradição" auferiu no meio acadêmico, sobretudo o brasileiro. Ademais dessas considerações, verifica-se ainda que a denominada gramática tradicional costuma figurar nos textos de descrição linguística mais recentes como um contraponto à nova teoria que se busca aplicar ao tratamento de determinado tema, não raro em situação de desvantagem. Essa, por sinal, foi a perspectiva por que articulamos a análise das denominadas palavras denotativas e de realce em um trabalho publicado há alguns anos, no qual as teses da semântica argumentativa de Oswald Ducrot caminham pari passu com as tentativas de descrição engendradas no âmbito da tradição filológica e estruturalista

\footnotetext{
${ }^{19}$ Esta gramática foi amplamente reformulada em subsequentes edições, com ampliação do rol de autores.
} 


\section{REVISTA DA ABRALIN}

(CAVALIERE, 2009). Não há, cremos, impropriedade na estratégia, se se considerar sempre a necessária leitura do texto antigo à luz de sua episteme.

\section{A crítica à gramática tradicional}

Estabelecida essa noção peculiar da gramática tradicional, que, conforme reiterado, mostra-se "nebulosa" por ser muito abrangente, e considerada sua finalidade dual de caráter científico e pedagógico, severas críticas emergem na identificação de suas falhas em ambos os planos. No plano pedagógico, a gramática tradicional é rotulada de anacrônica e purista; no científico, a gramática tradicional é insipiente e ineficaz. Em que medida essa avaliação depreciativa pode ser explicada?

\subsection{Gramática tradicional: anacronismo e purismo}

A princípio, destaca-se a percepção de que a crítica quase sempre resulta da má formação dos linguistas na avaliação historiográfica de textos escritos no passado, uma vez que não levam em conta fatores contextuais, tais como os parâmetros axiológicos que cada época confere ao texto pedagógico. Com efeito, a referência crítica que os linguistas contemporâneos fazem a essa gramática tradicional, tão ampla e diversa, decorre de equívocos metodológicos a respeito da valorização do fato histórico, o que é obviamente consequência de seu mau preparo ou mesmo da falta de formação profissional para lidar com questões historiográficas.

Um desses equívocos diz respeito à postura anacrônica de julgar o passado com valores do presente. Ao discorrer sobre procedimentos de períodos passados, o intérprete deve evitar a distorção de seu sentido original, principalmente mediante estabelecimento da dimensão exata de sua base axiológica. Isso implica discutir, por exemplo, em que medida ser pedagogicamente "normativo" é reprovável no século XIX, bem como o que significa ser excessivamente purista em períodos distintos como o da gramática racionalista e da gramática estruturalista. Pode-se observar, ordinariamente, sensível falta de consideração do clima intelectual dos diferentes momentos da história da pedagogia das línguas, como se valores como purismo e vanguardismo não sofressem alteração no decurso do tempo.

Em seu conhecido The invention of tradition, Eric Hobsbawn (1917-2012) e Terence Ranger (19292015) argumentam que muitos princípios, crenças e valores que parecem antigos são, na realidade, muito recentes e, às vezes, até fictícios (2000, p 1). Os autores distinguem "tradição genuína" de "tradição inventada", ressaltando (1983, p. 1): 


\section{REVISTA DA ABRALIN}

[A tradição inventada é] "um conjunto de práticas, normalmente regidas por regras clara ou tacitamente aceitas, de natureza ritual ou simbólica, que buscam inculcar certos valores e normas de comportamento por repetição, o que implica automaticamente a continuidade com o passado". ${ }^{20}$

De fato, a referência reiterada à gramática tradicional nos estudos linguísticos atuais segue esta perspectiva de "tradição inventada", no sentido de que semelhante referência se impõe como contraponto obrigatório ao aspecto revolucionário ou inovador das teorias modernas. Legitimar as novas abordagens implica necessariamente uma negação das propostas que têm circulado na comunidade científica, de tal sorte que uma característica negativa como a do prescritivismo exacerbado, que deveria ser atribuída apenas a uma determinada gama de gramáticas escritas em períodos específicos, acabou por abranger todas as gramáticas escritas no passado. Em outros termos, há, em geral, um viés tendencioso na maioria das referências à tradição gramatical que a situa como uma espécie de contraponto necessário ao elogio que normalmente é feito aos avanços da linguística como ciência. Mesmo os historiadores da linguística mais experientes às vezes se deixam seduzir por esse procedimento inidôneo, que não contribui em nada para uma avaliação livre e precisa dos textos que construíram conhecimentos sobre a língua e seu uso social.

\subsection{Gramática tradicional: insipiência e ineficiência}

Em outra dimensão, observam-se referências reiteradas à tradição gramatical como repositório de estudos ineptos, sem especificar claramente que autores ou obras são efetivamente objeto de reprovação. A rigor, parte-se da premissa de que tudo o que foi escrito antes de determinada ocasião é igual, lamentavelmente igual, de tal sorte que, uma vez escrito no passado, o texto é necessariamente insipiente. Conforme já aqui observado, a referência a essa tradição inespecífica serve de contraponto retórico para o elogio das novas tendências da linguística. Tal atitude é típica de linguistas que expressam seu julgamento sem a necessária neutralidade epistemológica (cf. AUROUX, 1989, p. 16)

Esse foi, por exemplo, o caminho escolhido por John Lyons (1932-2020) em sua referência depreciativa à gramática tradicional como estratégia argumentativa para elogiar a linguística formal do século XX. Entusiasmado com as conquistas da gramática gerativa no campo da gramaticalidade, Lyons assim se expressa (1981, p. 106-107):

\footnotetext{
A gramática tradicional oferece uma explicação bastante incompleta e, muitas vezes, insatisfatória acerca do conceito de gramaticalidade (...) A teoria gramatical moderna, especialmente no que diz respeito à formulação das regras sintáticas do sistema linguístico, logra ser mais elucidativa e abrangente do que a gramática tradicional jamais aspirou ser (...) Outra razão pela qual a gramática tradicional falhou - na realidade, sequer se empenhou - em prover uma descrição abrangente e esclarecedora da
}

\footnotetext{
${ }^{20}$ No original, "a set of practices, normally governed by overtly or tacitly accepted rules and of a ritual or symbolic nature, which seek to inculcate certain values and norms of behavior by repetition, which automatically implies continuity with the past".
} 


\title{
REVISTA DA ABRALIN
}

sintaxe das línguas com as quais lidou está no fato de que muito da sintaxe foi, explícita ou implicitamente, extraído do bom senso ou, para usar um termo mais grandiloquente, das leis da razão. ${ }^{21}$

Observe-se o uso da expressão "leis da razão" que, nesta crítica, situa a gramática tradicional dentro do modelo racionalista de Port-Royal, que cedeu proeminência à gramática histórico-comparativista no século XIX. Em sua crítica, Lyons se esquece de que o modelo gerativo de Noam Chomsky, que melhor tratou o conceito de gramaticalidade, mantém laços paradigmáticos exatamente com o modelo racionalista.

No Brasil, a situação não é diferente, embora a crítica à tradição tenha marca mais generalista por causa do conceito ainda menos preciso sobre o que é gramática tradicional. Leiamos o que afirma o linguista Mario Perini no prefácio da Gramática descritiva do português (2007, p. 14):

\begin{abstract}
Existe um lugar para a gramática no ensino de primeiro e segundo graus, lugar atualmente ocupado por uma doutrina gramatical que prescinde de toda a lingüística dos últimos setenta anos - e, na verdade, também de boa parte da lingüística anterior. Trata-se da gramática tradicional; ou, melhor dizendo, da versão atual, seriamente empobrecida, da velha gramática tradicional [...]

Sustento a idéia de que é responsabilidade dos lingüistas brasileiros elaborar uma descrição ampla e detalhada da realidade lingüística do Brasil. Entendo essa descrição como abrangendo não só a estrutura da língua padrão (objeto da minha Gramática), mas ainda a descrição da língua coloquial, sua variação social e geográfica, sua história etc.
\end{abstract}

A referência de Perini ao fracasso da tradição gramatical serve-se do mesmo papel argumentativo do contraponto: a descrição da língua hoje é eficiente porque se distingue do que se fez no passado. Mas o que realmente importa nessa referência à tradição gramatical é sua natureza difusa: que doutrina gramatical seria essa que "prescinde de toda a linguística dos últimos setenta anos"? Para admitir uma afirmação tão generalista e abrangente, devemos acatar a hipótese de que nada do modelo estruturalista, por exemplo, está nas páginas da tradição gramatical brasileira; que nada das teses funcionalistas chamou a atenção dos gramáticos tradicionais. Em outras palavras, devemos acreditar que a descrição gramatical não vai além de uma lista de conceitos sem qualquer embasamento teórico, como se fosse possível praticar a arte gramatical sem o apoio da teoria linguística.

Posições como a acima citada, por outro lado, fazem-nos recordar o conceito de "essential tension" a que Thomas Kuhn se refere ao afirmar que conceitos convergentes são tão essenciais para o progresso da ciência quanto os divergentes, de tal sorte que "somente pesquisas firmemente estabelecidas na tradição científica contemporânea são capazes de derrubá-la e fazer surgir uma nova

\footnotetext{
${ }^{21}$ No original, "Traditional grammar gave only a very partial and often highly inexplicit account of grammaticality (...) Modern grammatical theory sets out to be more explicit and more comprehensive, especially in respect of the formulation of the syntactic rules of language-systems, than traditional grammar ever aspired to be (...) Another reason why traditional grammar not only failed, but did not even try, to provide a comprehensive and fully explicit account of the syntax of the languages that it dealt with, was that much of syntax was held, explicitly or implicitly, to be determined by common sense or, to use a more grandiloquent term, the laws of thought.
} 


\section{REVISTA DA ABRALIN}

tradição" (1977, p. 226) 22. Em outros termos, a iconoclastia é um degrau necessário para a alçar-se à mudança de paradigma, razão por que o cientista cuja pesquisa resulta em uma nova ordem paradigmática deve necessariamente ter desempenhado o duplo papel de tradicionalista e iconoclasta.

\section{A gramática tradicional no Brasil: crise de identidade}

Um percurso rápido pelos dois séculos de gramatização do português no Brasil revela-nos cinco vertentes bem identificadas:

a) a gramática racionalista, que vige do início do século XIX a meados do século XIX, sob inspiração das teses residentes em César Chesneau Dumarsais (1676-1756), Étienne Bonnot de Condillac (1715-1780), Nicolas Beauzée (1717 - 1789) e Jerônimo Soares Barbosa (1837-1916). São exemplos desta fase o Compêndio da gramática filosófica da língua portuguesa (1859 [1929]), de Antônio da Costa Duarte (?-?), a Gramática portuguesa (1871[1866]), de Francisco Sotero dos Reis (1800-1871) e a Nova gramática analítica da lingua portuguesa (1880), do suíço Charles Adrian Grivet (1815-1876).

b) a gramática científica, que revoluciona o panorama teorético do final do século XIX com a implementação do naturalismo linguístico de August Schleicher (1821-1868) e sob influência de comparativistas como Jakob Grimm (1785-1863), Max Müller (1823-1900), William Whitney (1827-1894), entre outros. Citem-se a Gramática portuguesa (1881), de Júlio Ribeiro (1845-1890) e a Gramática da língua portuguesa (1907 [1887]), de Manuel Pacheco da Silva Júnior (1842-1899) e Boaventura Plácido Lameira de Andrade (?-1897).

c) a gramática filológica, que se apresenta a partir do início do século XX como expressão da análise linguística através do texto com sensível tendência diacrônica, em cujas bases estão expoentes da filologia românica e portuguesa como Friedrich Diez (1794-1876), Francisco Adolfo Coelho (1847-1919), Wilhelm Meyer-Lübke (1861 - 1936), José Leite de Vasconcelos (1958-1941), José Joaquim Nunes (1859 -1932) e Carolina Michaëlis de Vasconcelos (1851-1925). São exemplos os textos Lições de português (1923), de Álvaro Ferdinando Sousa da Silveira (1883-1967) e a Gramática expositiva da língua portuguesa (1937), de Mario Pereira de Sousa Lima (1883-?).

d) a gramática filológico-estruturalista, em que a tradição filológica converge com os princípios do estruturalismo linguístico que chegam ao Brasil a partir dos anos 1940, na esteira de Ferdinand de Saussure (1857-1913), Nikolai Trubetzkoy (1890-1938), Joaquim Mattoso Camara Jr. (1904-1970), Samuel Gili Gaya (1892-1976), Charles Bally (1865-1947), André Martinet (1908-1999) entre outros. Exemplos desta fase estão na Gramática normativa da língua portuguesa (1957), de Carlos Henrique da Rocha Lima (1915-1992), Moderna gramática portuguesa (1961), de Evanildo Bechara e Gramática fundamental da língua portuguesa (1968), de Gladstone Chaves de Melo (1917-2001).

\footnotetext{
${ }^{22}$ No original, "only investigations firmly rooted in the contemporary scientific tradition are likely to break that tradition and give rise to a new one".
} 


\section{REVISTA DA ABRALIN}

e) a gramática diversificada, típica do final do século XX, que desconsidera a tradição filológica e busca descrever o vernáculo à luz das novas (e diversificadas) correntes da linguística teórica, tais como o variacionismo linguístico laboviano, a gramática gerativa e o funcionalismo coseriano. Exemplos deste período encontram-se em A gramática gerativa (1976), de Mário Perini, Gramática de texto (1986), de Madre Olívia (1913-1994) e Regina Célia Pagliucci da Silveira, Moderna gramática portuguesa [segunda versão] (1999), de Evanildo Bechara, Gramática de usos do português (2000), de Maria Helena de Moura Neves, entre outros títulos.

As quatro primeiras vertentes, embora situem-se em bases teóricas distintas, coincidem em alguns aspectos: a) pautam-se em corpus de língua escrita literária; b) têm por escopo o ensino da língua vernácula; c) têm necessário caráter normativo, embora possam ter também caráter descritivo; d) destinam-se tanto a leitores leigos quanto a leitores especialistas; d) utilizam, em termos genéricos, a mesma metalinguagem. Por outro lado, são divergentes em alguns aspectos relevantes, tais como: a) a finalidade da gramática, que pode ser meramente normativa (gramática racionalista) ou descritivo-normativa (gramáticas científica, filológica, filológico-estruturalista); b) a sinopse da descrição gramatical, cujas bases seguem o modelo quaternário em ortografia, prosódia, sintaxe e etimologia (gramática racionalista), binário em lexicologia e sintaxe (gramática científica) ou terciário em fonética, morfologia e sintaxe (gramática filológico-estruturalista); c) a natureza do corpus, que é composto de autores clássicos (gramática científica e gramática filológica) ou de autores clássicos e contemporâneos (gramática filológico-estruturalista); d) a pluralidade de conceitos-chave da linguística, como o de classes gramaticais, funções sintáticas, elementos estruturais do substantivo e do verbo etc.

A percepção que nos traz a análise historiográfica é de que os fatores identitários acima referidos conferem uma feição unitária aos quatro primeiros perfis gramaticais, ou seja, na avaliação geral dessas quatro tradições, há uma prevalência dos traços de identidade sobre os traços de distinção. Esse fato dá a impressão de que todas as vertentes pertencem à mesma origem ou a uma única tradição. De certa forma, é compreensível que seja assim, porque sabemos que, quando falamos da origem da tradição linguística, não estamos falando de um evento isolado, mas de um processo que perdura por tempo considerável, durante o qual o conhecimento prévio se soma ao conhecimento novo: uma tradição originada na "transferência de tecnologia". Para linguistas experientes, porém, principalmente para aqueles que têm formação historiográfica, essa referência genérica a uma tradição unitária soa indevida, inscreve-se no conceito de "tradição inventada" a que se refere Eric Hobsbawn.

No Brasil, o surgimento da quinta vertente, a que denominamos "gramática diversificada", rompe com os cânones das tradições anteriores: o compromisso com norma linguística não é imperativo, o corpus em que se baseia a descrição tem natureza plural (texto escrito literário, texto escrito não literário, texto oral) e seu escopo não é necessariamente pedagógico. Por outro lado, a maioria dos textos gramaticais desse momento destina-se apenas ao leitor especialista, com formação na área de letras e linguística, de que resulta não ser incomum o uso de metalinguagens significativamente distintas em cada um deles. Com efeito, a expansão dos cursos de graduação em Letras nas últimas décadas do século XX, bem como a chegada de novos modelos de investigação linguística, tais como 


\section{REVISTA DA ABRALIN}

a gramática gerativa, a sociolinguística variacionista, a linguística textual e o funcionalismo linguístico, fizeram surgir no cenário acadêmico um pesquisador que se dedica à produção de textos gramaticais com outro perfil teleológico, destinados ao estudo superior da língua.

Além disso, esses novos modelos não apenas rompem a metalinguagem relativamente unificada das tradições anteriores, como também multiplicam os diferentes aparatos metalinguísticos, uma consequência natural do aspecto multifacetado que a linguística assume no final do século. Com isto, cria-se imageticamente, no plano da tradição inventada, uma dicotomia, dir-se-ia, talvez, uma antinomia, entre a tradição da gramática diversificada (por muitos denominada "gramática linguística") e todas as tradições anteriores, que passam a ser reunidas sob o manto da "gramática tradicional". Em outros termos, o processo de continuidades e descontinuidades que caracteriza a presença de ao menos cinco tradições - a gramática racionalista, a gramática científica, a gramática filológica, a gramática filológico-estruturalista e a gramática diversificada - passa a ser de apenas duas: gramática tradicional e gramática linguística, conforme se observa no quadro a seguir.

\begin{tabular}{ll|} 
Gramática tradicional & $\left\{\begin{array}{l}\text { gramática racionalista } \\
\text { gramática científica } \\
\text { gramática filológica } \\
\text { gramática filológico-estruturalista }\end{array}\right.$ \\
Gramática linguística $\rightarrow$ gramática diversificada
\end{tabular}

QUADRO 1 - A "tradição inventada" no Brasil.

\section{Concluindo}

Em dado momento deste trabalho, referimo-nos ao hábito de se "fazer uma visita" à tradição gramatical em capítulos iniciais de dissertações e teses acadêmicas. E o resultado, com as exceções que confirmam a regra, é caótico: selecionam-se alguns títulos, sem critério paradigmático ou sequer cronológico, de tal sorte que textos racionalistas irmanam-se a textos cientificistas ou mesmo filológicos, em um pontilhar de conceitos heterogêneos que, por vezes, são até colidentes entre si. Vivese a ilusão da tradição inventada, um desserviço para a descrição científica idônea e produtiva. Se o propósito é saber como pensavam os antigos, lembremo-nos de que a gramática do português no Brasil já conta com mais de dois séculos, pouco tempo, se considerarmos a história da gramatização, mas tempo suficiente para ter produzido mentes brilhantes e divergentes.

Por outro lado, não resta dúvida de que a referência mais criteriosa, que reúne textos de um mesmo momento ou paradigma, encontra obstáculos quase intransponíveis, tais como o acesso à bibliografia mais antiga, aos textos seminais, cuja presença é rara em bibliotecas de menor porte. $\mathrm{O}$ fato traz à tona o reiterado clamor pela criação de programas de digitalização de textos linguísticos e sua disponibilidade para consulta eletrônica. Decerto que são projetos custosos, dependentes de investimento, mas imperativos para que se democratize o acesso às fontes bibliográficas. Com tais 


\section{REVISTA DA ABRALIN}

projetos, ficará o pesquisador mais à vontade para selecionar as fontes de consulta e obter resultados mais precisos em sua pesquisa.

\section{REFERÊECIAS}

BECHARA, Evanildo. Moderna gramática portuguesa. São Paulo: Companhia Editora Nacional, 1961.

BECHARA, Evanildo. Moderna gramática portuguesa. Rio de Janeiro: 39. ed. Editora Lucerna, 1999.

DUARTE, Antonio da Costa. Compendio da grammatica philosophica da lingua portuguesa; acolhida pela Congregação do Licêo do Maranhão para o uso do mesmo Licêo, e das aulas de primeiras lettras da província. 4 ed. Maranhão: Typ. do Frias, 1859 [1829].

GRIVET, A. Nova grammatica analytica da lingua portugueza. Rio de Janeiro: Typ. de G. Leuzinger \& Filhos, 1881

MATEUS, Maria Helena Mira, Brito, Ana Maria; Duarte, Inês Silva e Faria, Isabel Hub. Gramática da língua portuguesa. elementos para a descrição da estrutura, funcionamento e uso do português actual. Coimbra: Livraria Almedina, 1983.

MELO, Gladstone Chaves de. Gramática fundamental da língua portuguesa. Rio de Janeiro: Livraria Acadêmica, 1968.

NEVES, Maria Helena de Moura. Gramática de usos do português. São Paulo: Editora Unesp, 2000.

OLÍVIA, Madre e Silveira, Regina Célia Pagliucci da. Gramática de texto, as relações-valores. São Paulo: Editora Cortez, série Gramática Portuguesa na Pesquisa e no Ensino, 1986.

PERINI, Mário. A gramática gerativa. Belo Horizonte: Editora Vigilia, 1976.

REIS, Francisco Sotero dos. Grammatica portugueza, acomodada aos principios geraes da palavra seguidos de immediata applicação pratica. 2 ed. Maranhão: Typ. de R. d'Almeida \& C., 1871 [1866].

ROCHA LIMA, Carlos Henrique da. Gramática normativa da língua portuguesa. Rio de Janeiro: José Olympio, 1957.

SAID ALI, Manuel. Dificuldades da língua portuguesa. Rio de Janeiro: Academia Brasileira de Letras, Coleção Antônio de Morais Silva, v. 7, 2008 [1908].

SILVEIRA, Alvaro Ferdinando Sousa da Rio de Janeiro. Lições de português. Revista de Língua Portuguesa, n. 24, 1923.

SOUSA LIMA, Mário Pereira de. Gramática expositiva da língua portuguesa para uso das escolas secundárias. São Paulo: Companhia Editora Nacional, 1937.

SILVA JÚNIOR, Manuel Pacheco da; Andrade, Boaventura Lameira de. Grammatica da lingua portugueza para uso nos gymnasios, lyceus e escolas normaes. 3. ed. Rio de Janeiro: Livr. Classica de Alves, 1907 [1887].

RIBEIRO, Julio. Grammatica portugueza. São Paulo: Typ. De Jorge Seckler, 1881. 


\title{
REVISTA DA ABRALIN
}

\author{
REFERÊNCIAS SECUNDÁRIAS
}

ADRADOS, Francisco Rodríguez. Lingüistica estructural. Madrid: Gredos, v. 1, 1969.

ALLEN, Keith. The Western classical tradition in linguistics. 2. ed. (expanded). London: Equinox Publishing Ltd. 2009.

AUROUX, Sylvain. A revolução tecnológica da gramatização [Trad. Eni Puccinelli Orlandi]. Campinas: Editora da Unicamp, 1992

AUROUX, Sylvain. Introduction. In: Auroux, Sylvain (Org.). Histoire des idées linguistiques. La naissance des métalangages en Orient et en Occident. Liège-Bruxelles: PierreMardaga, Éditeur, 1989.

CARVALHO, José Gonçalo Herculano de. Teoria da linguagem; natureza do fenómeno linguístico e a analise das línguas. Coimbra: Atlântida Editôra, 1969.

CAVALIERE, Ricardo. Afinal, que é gramática tradicional? Ciclo de Conferências A Academia e a Língua Portuguesa. Rio de Janeiro: Academia Brasileira de Letras, 17.nov.2015. Disponível em https://www.academia.org.br/videos/ciclo-de-conferencias/afinal-que-e-gramatica-tradicional. Acesso 5 de julho de 2021.

CAVALIERE, Ricardo. Palavras denotativas e termos afins: uma visão argumentativa. Niterói: EdUff, 2009.

CHEVALIER, Jean-Claude. Qu'entendre par 'grammaire traditionnelle'? Revue Québécoise de linguistique. v. 15, n. 2, 1986, p. 289-296.

COSERIU, Eugenio. Introducción a la lingüística. Edición electrónica. Madrid: Org. José Polo. Disponível em: https://pt.scribd.com/document/7332587/COSERIU-Eugenio-Introduccion-a-La-Linguistica. Acesso em: 5 julho de 2021.

der von GABELENTZ, Georg. Die Sprachwissenschaft, ihre Aufgaben, Methoden und bisherigen Ergebnisse. Leipzig: T. O. Weigel Nachfolger, 1891.

FOURNIER, Jean-Marie. Un example du transfert du modèle latin aux premières grammaires du français, l'analyse des temps du passé. In: Guimarães, Eduardo \& Barros, Diana Luz Pessoa de. History of Linguistics 2002: Selected Papers from the Ninth International Conference on the History of the Language Sciences. 27-30 São PauloCampinas August 2002. Amsterdam/Philadelphia: John Benjamins Publishing Company, 2007, p. 17-26.

FREDE, Michael. Essays in ancient philosophy. Minnesota: University of Minnesota Press, 1987.

GROSS, David. The past in ruins: tradition and the critique of modernity (critical perspectives on modern culture). Amherst: University of Massachusetts Press, 1992.

HOBSBAWN, Eric, Ranger, Terence. The invention of tradition. Cambridge: Cambridge University press, 2000

HYMES, Dell. Foundations in sociolinguitics: an ethnographic approach. Tavistock Publications, 2001.

HYMES, Dell. On Communicative Competence. In: Pride, J.B. and Holmes, J. (Eds.) Sociolinguistics. Selected Readings. Harmondsworth: Penguin, 1972, p. 269-293. 


\section{REVISTA DA ABRALIN}

KOERNER, E. F. K. Towards a historiography of linguistics: 19th and 20th century paradigms. In: Parret, Herman (Ed.). History of linguistic thought and contemporary linguistics. Berlin; New York: Walter de Gruyter (Foundations of Communication, 1975, p. 685-718.

KOERNER,. Models in linguistic historiography. In: Koerner, E. F. K. Practicing Linguistic Historiography. Amsterdam, Philadelphia: John Benjamins Publishing Company, p. 47-60, 1989.

KRETZMANN, Norman. Locke's semantic theory. In: Parret, Herman (Ed.). History of linguistic thought and contemporary linguistics. Berlin; New York: Walter de Gruyter (Foundations of Communication, 1975, p. 331-340.

KUHN, Thomas S. The structure of scientific revolutions. 2. ed., enlarged. Chicago and London: University of Chicago Press, 1970.

LIMA-HERNANDES, Maria Célia Pereira. Gramaticalização de combinação de cláusulas: orações de tempo no português do Brasil. São Paulo: USP, dissertação de mestrado, 1998, 140f.

LYONS, John. Language and linguistics: an introduction. Cambridge: Cambridge University Press, 1981.

MATTHEWS, Peter. A short history of structural linguistics. Cambridge: Cambridge University Press, 2001.

ROBINS, R. H. A short history of linguistics. London: Longman, 1967.

SEUREN, Pieter A. M. The subject-predicate debate x-rayed. In: Cram, David, Linn, Andrew R., Nowak, Elke (Eds.). History of Linguistics 1996, Traditions in Linguistics Worldwide. Selected papers from the Seventh International Conference on the History of the Language Sciences (ICHOLS VII), Oxford, 12-17 September 1996. Volume 1: Traditions in Linguistics Worldwide (). Amsterdam: Benjamins, 1999, p. 41-55.

TRENTMAN, John A. Speculative grammar and transformational grammar: a comparison of philosophical presuppositions. In: Parret, Herman (Ed.). History of linguistic thought and contemporary linguistics. Berlin; New York: Walter de Gruyter (Foundations of Communication, 1975, p. 279-201.

VIEIRA. Francisco Eduardo. A gramática tradicional; história crítica. São Paulo: Parábola Editorial, 2018.

WEBER, Max. Economy and Society: An outline of interpretative sociology (Trad. e Ed. G. Roth and C. Wittich). New York: Bedminster Press, 1968 [1921]. 